\title{
An Association of Total Health Expenditure with GDP and Life Expectancy
}

Sojib Bin Zaman*1, Naznin Hossain², Varshil Mehta ${ }^{3}$, Shuchita Sharmin ${ }^{1}$, Shakeel Ahmed Ibne Mahmood ${ }^{4}$

\section{ABSTRACT}

Introduction: Gradual total health expenditure (THE) has become a major concern. It is not only the increased THE, but also its unequal growth in overall economy, found among the developing countries. If increased life expectancy is considered as a leverage for an individual's investment in health services, it can be expected that as the life expectancy increases, tendency of health care investment will also experience a boost up.

Objective: The aim of the present study was to explore and identify the association of healthcare expenditure with the life expectancy and Gross Domestic Product (GDP) in developing countries, especially that of Bangladesh.

Methodology: Data were retrospectively collected from "Health Bulletin 2011" and "Sample Vital Registration System 2010" of Bangladesh considering the fiscal year 1996 to fiscal year 2006. Using STATA, multivariable logistic regression was performed to find out the association of total health expenditure with GDP and life expectancy.

Results: A direct relationship between GDP and total health expenditure was found through analysing the data. At the individual level, income had a direct influence on health spending. However, there was no significant relationship between total health expenditure with increased life expectancy.

Conclusion: The present study did not find any association between life expectancy and total health expenditure. However, our analysis found out that total health expenditure is more sensitive to gross domestic product rather than life expectancy.

Keywords: Total Health Expenditure, Life Expectancy, GDP, Bangladesh.

\section{Introduction}

The rapid growth of the total health expenditure (THE) has become a topic of major concern in most of the developing countries [1]. A large amount of fund is being exchanged between the households and health care services through service providing agencies. Therefore, out-of-pocket money spending in parallel with governing expenditures to buy the health services, have become a burning concern especially for the third world countries [2]. In such reality, total health expenditure is defined as the sum of both public and private health spending in consideration of the ratio of total population of the country [3]. It covers both the preventive and curative services along with emergency and rehabilitative health services for the entire population [4].

In general, Ministry of Finance of a country allocates the considerable portion of budget for health expenditure in a fiscal year. However, this allocated budget has been reported in different studies as unequal for the developed and developing countries [3]. Other study showed that income has a direct influence on health spending for an individual and therefore, rich people are found to be more concerned about their

\section{Article Details}

Date Received: 07/05/2017 Date Revised: 11/05/2017 Date Accepted: 11/05/2017 Date Published: 12/05/2017 DOI: 10.5281/zenodo. 576546 Editor(s): Shakti Goel

\section{Author Affiliation}

1. Department of Development Studies, University of Dhaka, Bangladesh.

2. Department of Pharmacology, Dhaka Medical College, Bangladesh.

3. MGM Medical College, Navi Mumbai, India.

4. Department of Community Medicine and Clinical Epidemiology, University of Newcastle, Australia.

\section{Corresponding Author}

Sojib Bin Zaman

Address: Department of Development Studies, University of Dhaka, Bangladesh. Email I'd: sojibbz@gmail.com

Copyright: (c) 2017. The Author(s). This is an open access article under the CC BY license. (http://creativecommons.org/lice nses/by/4.0)

\section{Financial or Comepeting} Interest: None

\section{Cite as:}

Zaman, S., Hossain, N., Mehta, V., Sharmin, S., \& Mahmood, S. (2017). An Association of Total Health Expenditure with GDP and Life Expectancy. Journal of Medical Research And Innovation, 1(2), AU7-AU12. doi:10.5281/zenodo.576546 
well-being than the marginalized group [5]. Increased life expectancy has a significant influence on investment in the health-care sector that makes people to buy a good premium of health insurance or spend money directly. In a marketbased economy, private investors are willing to finance in establishing medical industry which will be able to provide advanced diagnostic method and modern treatment facilities [6]. As the resources are scarce in developing countries, Ministry of Health (MoH) also depends on foreign aid to ensure the provision of health service coverage for all the citizens. If $\mathrm{MoH}$ can increase the allocation of budget in the health sector, individual spending as out-of-pocket expenditure is expected to reduce significantly. Out-of-pocket payments and government health expenditure are not the same where else they have different impacts on financial risk protection [2]. Extra individual expenditures on health can lead to a catastrophic effect on the financial status of the people, especially that of the poor people.

Determination of a country's health spending depends on many factors, in other words, there are priority and nonpriority area of a country [7]. Total government spending, as a share of GDP, can be different according to the country's priorities which depends on capacity to pay and fiscal constraints of a financial year [1]. Demographic aspects like distribution of young-older population, urban-rural ratios, and burden of communicable and non-communicable diseases reflect the amount of needed money for the health system [4]. However, a good health system indicator and application of technology in health care always tend to exhibit a positive impact on health expenditure [8]. Due to technological advancement, reduced maternal and child mortality, and improved health care delivery system; people from most of the countries can enjoy high survival chances [8]. However, life expectancy is also unequally distributed globally. For example, life expectancy is often better in the developed countries, as compared to that of the developing countries. However, increasing longevity might be considered negatively for the economy of developing countries. Elderly population requires an extra care and more sophisticated health-care services, which could result in higher health expenditure. In this context, there exists controversies as to whether health expenditure depends on the overall income of a country or not. Again, it is unknown as to whether an increased life expectancy can influence the health care spending in the developing countries. In the presence of such gap in knowledge, the present study is an attempt to identify an association of the life expectancy with healthcare expenditure and GDP in Bangladesh.

\section{Methodology}

Total health expenditure and GDP were collected for the year of 1996 to 2006 from "Bangladesh Health Bulletin 2011" and the life expectancy for the same period was taken from "Sample Vital Registration System 2010" respectively. These secondary data should be considered authentic as these data were generated by the Government of Bangladesh (table 1). To compare life expectancy with the total health expenditure, fiscal year has been considered. Total health expenditure and GDP were expressed using both the Bangladeshi taka (BDT) and USD (\$).

\section{Variables and measurements}

Total health expenditure includes all of the payments like spending for doctor's consultation fees, medication, laboratory tests and hospital bills. In developing countries, prepayments, payroll tax, user fee, public insurance and voluntary insurance contribute in general taxation. The term life expectancy means an expectation of longevity i.e. expected years for a person to survive. Here our dependent variable is total health expenditure (THE) and independent variables are life expectancy and GDP.

\section{Statistical Analysis}

All the analyses were performed using STATA version 13 SE (College Station, Texas, USA). Graphical presentation and descriptive statistics were performed to present the findings. Multivariate logistic regression was carried out to find the association of total health expenditure with life expectancy and GDP. A conventional cut-off value of 0.05 was taken as statistical significance.

\section{Results}

In this study, we found a direct relationship of total health expenditure and life expectancy in bi-variable analysis. Chart 1 shows that with the increased investment of health expenditure, life expectancy showed a heightened trend in Bangladesh from 1996 to 2006 fiscal year.

Considering the multivariable analysis, the behaviour of Total Health Expenditure (THE) in relation to GDP and Life Expectancy (LE) has been discussed. A priori was considered expecting that both the GDP and LE will have a positive impact on THE. Thus our proposed econometric model is: THE $=\beta 1+$ $\beta 2 \mathrm{GDP}+\beta 3 \mathrm{LE}+\mathrm{Se}$.

Here, $\beta 1$ is the intercept and Se is an error or residual value. This equation has considered $\beta 2$ and $\beta 3$ as the slope for the independent variable of GDP and LE, respectively. 


\begin{tabular}{|c|c|c|c|c|c|}
\hline Fiscal year & $\begin{array}{c}\text { THE in BDT } \\
\text { (Lakh) }\end{array}$ & $\begin{array}{c}\text { THE in \$ } \\
\text { (Million) }\end{array}$ & $\begin{array}{c}\text { GDP in BDT } \\
\text { (Lakh*) }\end{array}$ & $\begin{array}{c}\text { GDP in \$ } \\
\text { (Million) }\end{array}$ & $\begin{array}{c}\text { Life } \\
\text { expectancy } \\
\text { (Year) }\end{array}$ \\
\hline $\mathbf{1 9 9 6}-\mathbf{1 9 9 7}$ & 393 & 0.50 & 14571 & 18.68 & 58.9 \\
\hline $\mathbf{1 9 9 7}-\mathbf{1 9 9 8}$ & 426 & 0.55 & 15901 & 20.39 & 60.1 \\
\hline $\mathbf{1 9 9 8}-\mathbf{1 9 9 9}$ & 466 & 0.60 & 17209 & 22.06 & 61.5 \\
\hline $\mathbf{1 9 9 9}-\mathbf{2 0 0 0}$ & 506 & 0.65 & 18313 & 23.48 & 62.7 \\
\hline $\mathbf{2 0 0 0}-\mathbf{2 0 0 1}$ & 571 & 0.73 & 19499 & 25.00 & 63.6 \\
\hline $\mathbf{2 0 0 1}-\mathbf{2 0 0 2}$ & 624 & 0.80 & 20557 & 26.36 & 64.2 \\
\hline $\mathbf{2 0 0 2}-\mathbf{2 0 0 3}$ & 665 & 0.85 & 22298 & 28.59 & 64.9 \\
\hline $\mathbf{2 0 0 3}-\mathbf{2 0 0 4}$ & 742 & 0.95 & 24181 & 31.00 & 65.1 \\
\hline $\mathbf{2 0 0 5}-\mathbf{2 0 0 5}$ & 845 & 1.08 & 26747 & 34.29 & 65.2 \\
\hline $\mathbf{2 0 0 6}-\mathbf{2 0 0 7}$ & 988 & 1.27 & 29568 & 37.91 & 66.2 \\
\hline
\end{tabular}

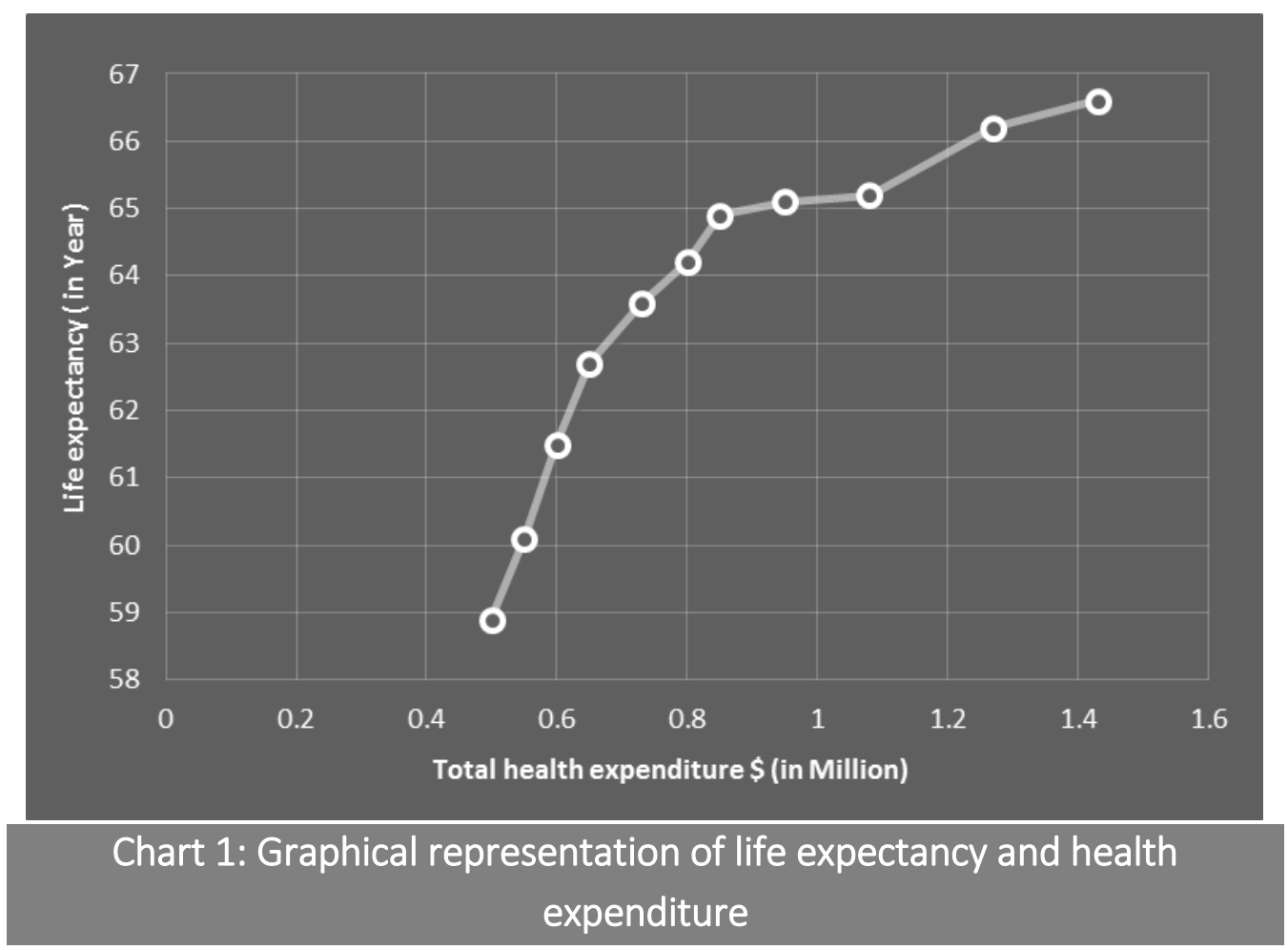

The fitted Regression Model was as below: Total health Expenditure $(\mathrm{THE})=183.34+.0432$ GDP- $7.313 \mathrm{LE}$. Se $=$ (.0018) (4.248) (234.23) $R^{2}=0.9972 ;$ Adjusted $R^{2}=0.9965$
Where figures in parentheses are the estimated standard errors (Se). Before the interpretation, we can observe the partial slope coefficient of GDP, namely 0.0432 . 
The interpretation of these regression coefficients are as follows:

0.0432 is the partial regression coefficient of GDP suggested that with the influence of LE held constant, as GDP increases 1 unit, on average total health expenditure goes up by 0.0432 units. To make it more economically interpretable, if the GDP rises by one lakh BDT ( USD 1300), on average, total health expenditure will increase up to 0.0432 lakh BDT ( USD 56.16). The negative coefficient -7.313 tells us that holding the influence of GDP constant, on average, total health expenditure goes down by about 7.313 lakh BDT (USD 9506) if life expectancy increases by 1 year. The intercept value is 183.34 which can be interpreted that if the values of GDP and LE were fixed at zero, the mean total health expenditure will be quiet high. The $\mathrm{R}^{2}$ value of 0.9972 means that about 99.72 percent of the variation in total health expenditure can be explained by GDP and LE. Therfore, the result reveals that GDP has significant effect on THE $(p<0.05)$.Again, in case of life expectancy, it shows a negative relationship, if LE increases by 1 unit, total health expenditure will be decreased 7.31 lakh BDT ( USD 9506). But statistically, there is no significant relationship between life expectancy and total health expenditure $(p>0.05)$.

\section{Discussion}

The present study did not find any statistical significance between the life expectancy and total health expenditure in multi variable analysis ( $p>0.05$ ). Based on findings of other studies, the assumption was made that if the life expectancy of a country increases, the tendency of health care spending will increase [9]. However, the present study contradicts the result of a previous study. Such finding might be attributed to a number of reasons in our study, notably the limited availability of health care data at the macro as well as the micro level.

However, another finding of this study regarding the relationship of GDP and health expenditure is consistent with previous study, which showed positive correlation between GDP and health expenditure; that is as GDP increase, health expenditure in general will be increased [1]. In the present study, we found a positive association between total government expenditure as a share of GDP which was consistence with a previous research finding. The previous study also observed that an increase in the total government expenditure could lead to a significant increase in health expenditures [10].

At this stage, it should be worth mentioning that in determining the income elasticity of health expenditure, the identification of the non-income determinants are essential for avoiding the effect of missing variable. However, this task of identification of the non-income determinants is reported to be difficult for a number of reasons. As an example, one such obstacle is the limited availability of health care data at the macro as well as micro level [4]. The missing variable effect would induce either a downward or an upward bias depending on the sign of correlation between the explanatory and the omitted variables. Moreover, many factors such as income, education, taxation, social security, and user fee depend on health expenditure [7]. It is assumed that more investment in health care delivery system and technological advancement in health science can increase human longevity [11]. Life expectancy can also be increased with improvement in the overall health system particularly focusing on health care of mother and children [12, 13]. In such context, collective effort is essential to bring the positive change in health financing and health expenditure throughout the health system by ensuring a good public health leadership [14].

From the literature point of view of the Organisation for Economic Co-operation and Development (OECD) countries, the health expenditure per capita on GDP consistently showed that income elasticity ranged between 1.20 and 1.50 [15]. Several studies conducted in OECD countries used the panel data and found that income elasticity is larger if it is more than 1.00 for a country [16]. However, contradictory results also exist. One study did not find any significant relationship with the government health expenditure and the share of annual GDP [17]. Farag et al. (2009) examined the panel data from 1995 to 2006 which were derived from 44 countries where he found that $1 \%$ increase in GDP was associated with $0.66 \%$ increase in government health expenditure for the developing countries and $0.96 \%$ increase for the middle to high-income countries. Therefore, GDP could be considered as a function of healthcare expenditure [6]. If we consider health as a component of human capital along with education, it might show us the reverse causation.

According to Wagstaff (2009), there are at least two mechanisms through which GDP can act as a function of healthcare expenditures [18]. Firstly, if the health expenditure is regarded as an investment in human capital, and this human capital could generate a good source of income. Consequently, this revenue would ultimately increase the health care expenditure which in turn might propel the GDP higher. Secondly, healthcare expenditure could shape the health system in such a way that every citizen could enjoy relatively good health and it could have transformed the human capital in producing labour supply and productivity. Finally, there are many predictive factors such as income, technological prosperity and variety in medical services and health system characteristics which need to be considered in 
calculating the total health care expenditures [19]. Although income shows positive relation to health care expenditure, the conclusion regarding the elasticity of revenue is not yet very much certain [20]. However, results from the previous studies showed that when GDP increases, health expenditure in general increases [7]. It is also quite evident that total government spending as a share of GDP has a positive association with the financial health budget.

\section{Limitations of the study}

Though, there was a lack of available time series data of recent years at the time of analysis, availability of 10 fiscal year data from 1996 to 2006 allowed the unique opportunity to explore the factors associated with health expenditure in Bangladesh. However, certain limitations remained and thus, results should be interpreted with great caution. The variables included in this study were still limited and some important variables were missing. Health system characteristics, such as the provider payment mechanisms and the degree of private provision of the services were not included in the study due to the lack of adequate time series data. Finally, some methodological issues remained problematic and challenging, that might imply new scope in analysing the panel data in future.

\section{Conclusion}

This present study not only analyses the relationship between incomes of a country with the total health expenditure but also shows the statistical relationship between the total health expenditure with the life expectancy. It was revealed that there was no significant relationship between the life expectancy and total health expenditure. Furthermore, the present article explains the reason of this kind of inverse relationship. The results show that total health expenditure is more sensitive to gross domestic product rather than life expectancy of a country. Through further analysis of longitudinal data for different developing countries, the typical association of health expenditure to GDP can be established.

\section{Acknowledgement}

We are grateful to the Government of Bangladesh to give us the permission in using the secondary data from Bangladesh Health Bulletin and Sample Vital Registration System.

\section{Authors' contribution}

SBZ developed the study concept and designed the study. SBZ and $\mathrm{NH}$ was responsible for data collection and drafted the manuscript. SBZ and NH participated in data analysis. VM, SS and SAIM edited the manuscript and contributed intellectually. All authors have read the final manuscript and agreed for submission.

\section{References}

1. Lu, C., Schneider, M., Gubbins, P., Leach-Kemon, K., Jamison, D., Murray, C. (2010). Public financing of health in developing countries: a cross-national systematic analysis. The Lancet 375(9723), 1375-87. https://doi.org/10.1016/S0140-6736

2. Zaman, S., Hossain, N. (2017). Universal Health Coverage: A burning need for developing countries. Journal of Medical Research and Innovation 1(1), 18-20. https://doi.org/10.5281/zenodo.546770

3. Musgrove, P., Zeramdini, R., Carrin, G. (2002). Basic patterns in national health expenditure. Bulletin of the World Health Organization 80(2), 134-46. https://doi.org/10.1590/S0042-96862002000200009

4. Hitiris, T., Posnett, J. (1992). The determinants and effects of health expenditure in developed countries. Journal of health economics 11(2), 173-81. https://doi.org/10.1016/0167-6296

5. Getzen, T. (2000). Health care is an individual necessity and a national luxury: applying multilevel decision models to the analysis of health care expenditures. Journal of health economics 19(2), 259-70. https://doi.org/10.1016/S0167-6296

6. Hansen, P., King, A. (1996). The determinants of health care expenditure: a cointegration approach. Journal of health economics 15(1), 127-37. https://doi.org/10.1016/0167-6296

7. Baltagi, B., Moscone, F. (2010). Health care expenditure and income in the OECD reconsidered: Evidence from panel data. Economic Modelling 27(4), 804-11. https://doi.org/10.1016/j.econmod.2009.12.001

8. Smith, S., Newhouse, J., Freeland, M. (2009). Income, insurance, and technology: why does health spending outpace economic growth?. Health Affairs 28(5), 127684. https://doi.org/10.1377/hlthaff.28.5.1276

9. Blomqvist, Å., Carter, R. (1997). Is health care really a luxury?. Journal of Health Economics 16(2), 207-29. https://doi.org/10.1016/S0167-6296

10. Fernandes, A., Xu, K., James, C., Saksena, P., Van, d., Carrin, G., et, al. (2013). General budget support: has it benefited the health sector?. Health economics 22(12), 1440-51. https://doi.org/10.1002/hec.2895

11. Zaman, S., Hossain, N., Ahammed, S., Ahmed, Z. (2017). Contexts and Opportunities of e-Health Technology in Medical Care. Journal of Medical Research and Innovation 1(2), AV1-AV4. https://doi.org/10.5281/zenodo.570870 
12. Rahman, A., Iqbal, A., Hoque, D., Moinuddin, M., Zaman, S., Rahman, Q., et, al. (2017). Managing Neonatal and Early Childhood Syndromic Sepsis in Sub-District Hospitals in Resource Poor Settings: Improvement in Quality of Care through Introduction of a Package of Interventions in Rural Bangladesh. PloS one 12(1), e0170267.

https://doi.org/10.1371/journal.pone.0170267

13. Zaman, S., Hossain, N., Yasir, A., Sharmin, S. (2017). Management of Newborn Infection: Knowledge and attitude among health care providers of selected subdistrict hospitals in Bangladesh. International Journal of Perceptions in Public Health 1(2), 127-32.

14. Zaman, S. (2017). Importance of Learning the Public Health Leadership. Public Health of Indonesia 3(1), 1-3.

15. Shaw, J., Horrace, W., Vogel, R. (2005). The determinants of life expectancy: an analysis of the OECD health data. . Southern Economic Journal 71(4), 768-783. https://doi.org/10.2307/20062079.
16. Gerdtham, U., Søgaard, J., Andersson, F., Jönsson, B. (1992). An econometric analysis of health care expenditure: a cross-section study of the OECD countries. Journal of health economics 11(1), 63-84. https://doi.org/10.1016/0167-6296

17. Leu, R. (1986). The public-private mix and international health care costs. Public and private health services $7(1)$, 41.

18. Wagstaff, A. (). Social health insurance vs. tax-financed health systems-evidence from the OECD. SSRN

19. Baker, L., Wheeler, S. (1998). Managed care and technology diffusion: the case of MRI. Health Affairs 17(5), 195-207. https://doi.org/10.1377/hlthaff.17.5.195

20. Farag, M., NandaKumar, A., Wallack, S., Hodgkin, D., Gaumer, G., Erbil, C. (2012). The income elasticity of health care spending in developing and developed countries. International Journal of Health Care Finance and Economics 12(2), 145-62. https://doi.org/10.1007/s10754-012-9108-z. 